$10^{\text {th }}$ International Conference on Modern Research in MANAGEMENT, ECONOMICS and ACCOUNTING

\title{
A study of new approaches to accounting education in Saudi Arabia
}

\author{
Msaeed Alghamdi \\ King Abdulaziz University
}

\begin{abstract}
Over the previous decades, there has been a big expectation gap between the investment made in the accounting education and the returns derived from the same. There have increased concerns by the accounting practitioners to initiate education reforms that will see students equipped with specialized knowledge that will enable them to perform certain tasks and maneuver in diverse situations in the workplace. This is aimed at preparing them to cope up with the reality eminent in the work environment today. On the other hand, academicians have shown an increased focus on the need for the accounting education to be more comprehensive and broad. In this paper we will explore the new approaches to accounting education in Saudi Arabia aimed at meeting the current requirements of the Profession by using utilizes abductive reasoning to explain the surprising facts that revolve around the accounting education in Saudi Arabia. The study starts by delving into in-depth facts regarding the accounting education in Saudi Arabia based on four critical aspects. These include IT alignment, teaching methods and student's skills, curriculum inefficiency, and alignment of the gained accounting skills with the real experiences in the workplace.
\end{abstract}

Keywords: Accounting practices; Accounting skills; IFRS; SOCPA; Teaching methods 